\title{
Current Understanding of the Acute Exacerbation of Chronic Rhinosinusitis
}

\author{
Dawei $W u^{1}$, Benjamin Saul Bleier ${ }^{2}$ and Yongxiang Wei ${ }^{1 *}$ \\ ${ }^{1}$ Department of Otolaryngology-Head and Neck Surgery, Beijing Anzhen Hospital, Capital Medical University, Beijing, China, \\ ${ }^{2}$ Department of Otolaryngology, Massachusetts Eye and Ear Infirmary, Harvard Medical School, Boston, MA, United States
}

OPEN ACCESS

Edited by:

Sarah Vreugde,

University of Adelaide, Australia

Reviewed by:

Richard George Douglas,

The University of Auckland,

New Zealand

Emily K. Cope,

Northern Arizona University,

United States

*Correspondence:

Yongxiang Wei

yongxw67@163.com

Specialty section:

This article was submitted to

Clinical Microbiology,

a section of the journal

Frontiers in Cellular and Infection

Microbiology

Received: 22 August 2019

Accepted: 20 November 2019

Published: 04 December 2019

Citation:

Wu D, Bleier BS and Wei Y (2019)

Current Understanding of the

Acute Exacerbation of Chronic

Rhinosinusitis.

Front. Cell. Infect. Microbiol. 9:415.

doi: 10.3389/fcimb.2019.00415
Background: Acute exacerbations of chronic rhinosinusitis (CRS) have been increasingly recognized as an important disease entity with a significant impact on the quality of life. There is a growing amount of research on the etiopathogenesis and management of acute exacerbations of CRS. This review aims to summarize the current literature and provide an overall understanding of acute CRS exacerbations.

Methods: A related literature review with the key terms of "chronic rhinosinusitis" and "exacerbation" was performed using PubMed.

Results: There is no consensus definition of the acute exacerbation of CRS. Impaired mucociliary clearance, atrophic rhinitis, and immunologic changes are important predisposing factors for acute CRS exacerbations. Current evidence supports the role of the transient viral infection as the initial inflammatory stimulus in the pathogenesis of acute CRS exacerbations. Secondary bacterial infection or microbial community dysbiosis within the sinonasal cavity is the main event during the acute exacerbation of CRS. Distinct changes in local and systemic immune responses during exacerbation provide new insights into the pathophysiology of CRS exacerbation. Although current guidelines suggest the use of short-term antibiotics in patients with acute CRS exacerbation for symptomatic relief, evidence-based treatment recommendations for acute CRS exacerbation are still lacking, and large-high-quality RCTs are required.

Conclusion: There have been significant advances in understanding the etiology and immunological feathers of acute CRS exacerbation. Nevertheless, consensus definition, diagnostic criterion, biomarkers to differentiate acute CRS exacerbation from CRS, assessment of disease severity, and evidence-based treatment options for acute CRS exacerbation are still lacking.

Keywords: Chronic rhinosinusitis, acute exacerbations, bacteria, virus, etiology, treatment

\section{INTRODUCTION}

Chronic rhinosinusitis (CRS) is a highly heterogeneous upper airway disease (Orlandi et al., 2016), which affects about 11-12\% of adults in western countries (Hastan et al., 2011; Hirsch et al., 2017) and $\sim 8 \%$ of the general population in China (Shi et al., 2015). It significantly impairs quality of life due to the chronic symptoms (Hoehle et al., 2016) and acute exacerbations of CRS (Phillips et al., 2017). Notably, one significant issue related to the care of CRS patients is concerning the acute 
exacerbations, which might account for increasing healthcare cost (Chung et al., 2014; Smith et al., 2015) and annual physician visits (Smith et al., 2013), as well as significant decreases in workplace productivity (Rudmik et al., 2014; Campbell et al., 2017). An acute exacerbation of CRS is defined as an acute and transient worsening of preexisting symptoms in patients with CRS (Fokkens et al., 2012), and the frequency of CRS exacerbations is recently identified as an independent predictor of quality of life (Phillips et al., 2017). Currently, triggers leading to CRS disease exacerbation are not well-characterized. However, patients with acute CRS exacerbation are mainly attributed to the bacterial infection, and therefore they are treated as acute rhinosinusitis with antibiotics in the leading guidelines (Fokkens et al., 2012; Peters et al., 2014; Banoub et al., 2018).

There are accumulating evidence supporting the critical role of sinus mucosal microbiome in the pathogenesis of CRS (Hamilos, 2014; Brook, 2016; Mahdavinia et al., 2016; Wagner et al., 2017; Sivasubramaniam and Douglas, 2018), either as a direct driver of chronic inflammation (Hamilos, 2015; Lan et al., 2018; Lee et al., 2018) or as being potentially involved in its exacerbation (Wood et al., 2011; Tan et al., 2017). The etiology of acute CRS exacerbation is usually a secondary bacterial infection that commonly begins with a viral upper respiratory tract infection (Cho et al., 2013; Rowan et al., 2015) or begins with microbial community dysbiosis within the sinonasal cavity (Brook et al., 2005; Brook, 2006). Furthermore, the acute exacerbations of CRS after endoscopic surgery are highly associated with bacterial infections (Bhattacharyya and Kepnes, 1999; Bhattacharyya et al., 2004; Ikeda et al., 2011). Although viral and bacterial infections are the main event during the process of acute exacerbation, factors influencing the dynamics of the nasal microbiota, pathogenic mechanisms exerted by microbial dysbiosis, and the association between the nasal microbiota and outer stimuli remain unclear. Recent studies have proved that patients with acute CRS exacerbation have distinct immunological changes (Rank et al., 2013; Divekar et al., 2015), and a series of risk factors for the acute exacerbations of CRS have been identified (Kuiper et al., 2018), which promotes the understanding of the complex pathogenesis of acute CRS exacerbation. This review will summarize the current knowledge on clinical and immunologic characteristics and medical treatment of acute CRS exacerbation.

\section{DEFINITION OF ACUTE EXACERBATION OF CHRONIC RHINOSINUSITIS}

There is no consensus definition of an acute exacerbation of CRS mainly due to the inconsistency in reporting of endpoints and the complex etiology of acute exacerbation. The International Consensus Statement on Allergy and Rhinology put forward the definition of AECRS that a sudden worsening of symptoms in a patient previously diagnosed with CRS, with a return to baseline symptoms after treatment (Orlandi et al., 2016). Similarly, the European Position Paper on Rhinosinusitis and Nasal Polyps 2012 (EPOS 2012) defined the AECRS based on the sudden worsening of preexisting sinonasal symptoms in patients with CRS (Fokkens et al., 2012). Furthermore, several empirical definition criteria have been widely used for research purposes. A study from Rank and colleagues defined a CRS exacerbation based on diagnosis coding and at least one of the following: a prescription for systemic antibiotics, systemic corticosteroids, plans for surgical intervention, emergency department or urgent care visit, or hospitalization for CRS (Rank et al., 2010). Similarly, Sedaghat and colleagues used three described metrics to assess the exacerbation frequency of CRS, the number of patient-reported (1) sinus infections, (2) CRS-related antibiotic courses, and (3) CRS-related oral corticosteroid courses, each in the last 3 months (Phillips et al., 2017; Banoub et al., 2018; Yamasaki et al., 2018). These direct treatment-related metrics of acute CRS exacerbation facilitate the quantitative research and assessment on the acute exacerbation of CRS, although there is a certain discrepancy between these metrics. It is necessary to put forward a wellrecognized diagnostic criterion that contains either symptombased or actual examination-based items.

It is also important to point out that recurrent acute rhinosinusitis (RARS), which shares a variety of symptoms with acute CRS exacerbation, is a distinct form of rhinosinusitis regarding anatomic variants (Sohn et al., 2018) and the number of previous sinus surgery (Poetker et al., 2008). RARS is defined by a threshold of 4 episodes of acute bacterial rhinosinusitis per year (Poetker et al., 2008; Bhattacharyya et al., 2012; Rosenfeld et al., 2015), and patients with RARS experience complete resolution of sinus-specific symptoms and have completed resolved sinus changes between episodes of acute bacterial rhinosinusitis (Barham et al., 2017). Furthermore, an appropriateness criterion for endoscopic sinus surgery in the management of adult RARS has been recently proposed to optimize the quality and value of surgical inventions (Rudmik et al., 2018).

\section{PREDISPOSING FACTORS FOR ACUTE CRS EXACERBATIONS}

Previous studies have focused on the mechanisms of CRS (Bachert et al., 2018; Cao et al., 2018), and the etiology of acute CRS exacerbation is not well-identified (Orlandi et al., 2016). There has been an increasing consensus that predisposing conditions including allergic rhinitis, nasal deformity, immune deficiency, and other environmental factors create an environment conducive to the viral infection (Tan et al., 2017) and the subsequent growth of bacteria (Brook, 2006; Ikeda et al., 2011; Bose et al., 2016), leading to acute exacerbations. CRS is characterized by a dysfunctional hostenvironmental interaction both in the epithelium and the subsequent immune response (Tieu et al., 2009; Fokkens et al., 2012; Schleimer, 2017). Therefore, there are some certain defects of host immune response associated with CRS predispose to acute CRS exacerbation when the triggers are involved. It has been reported that impaired mucociliary clearance and atrophic rhinitis in combination with CRS are important predisposing factors for acute CRS exacerbations (Hafner et al., 1997; Fokkens et al., 2012; Dutta and Ghatak, 2013). 


\section{INITIATING ROLE OF THE VIRUS IN THE ACUTE CRS EXACERBATION}

Similar to the initiating role of the virus in the exacerbation of acute rhinosinusitis (Eloy et al., 2011; Fokkens et al., 2012), there is evidence supporting the crucial role of the virus in the acute CRS exacerbation and rhinovirus is the most prevalent virus in patients with CRS exacerbation (Cho et al., 2013; Rowan et al., 2015). A recent systematic review by Basharat et al. showed that the prevalence of rhinovirus infections is increased in patients with CRS. Furthermore, rhinovirus infections incite inflammatory reactions that may result in CRS exacerbations and progression of disease (Basharat et al., 2019). Human bocavirus and metapneumovirus (hMPV) are also found in the nasal washes of CRS during flare-ups (Tan et al., 2017). Moreover, some other viruses, such as herpes virus, human cytomegalovirus, and Epstein-Barr virus, have identified in patients with nasal polyps, and it is still unclear whether they contribute to the acute CRS exacerbations (Costa et al., 2014). Previous in vitro studies have shown that respiratory viral infection can facilitate the invasion of bacteria into the nasal mucosa through directly damaging to the epithelial cells and impairing tight junctions (Yeo and Jang, 2010; Wang et al., 2012). Furthermore, viral infections have been reported to obstruct sinus ostia (Gwaltney et al., 1994), production of inflammatory mediators by nasal epithelial cells (Wang et al., 2009), and damage to the cilia (Pedersen et al., 1983). It has been proposed that the priming of the nasal epithelium against acute viral infection potentiates its environment to be suitable for secondary bacterial infection, which may further exacerbate the symptoms (Tan et al., 2017).

It should also be noted that most acute viral infections in patients with CRS are self-limiting, and the duration of symptoms lasts $<10$ days (Orlandi et al., 2016). Interestingly, several studies have pointed out that viral colonization did not increase the viral infection rate in patients with CRS compared with controls (Liao et al., 2014), and the persistence of respiratory viruses within sinonasal mucosa is unlikely to be a cause of ongoing inflammation in CRS (Wood et al., 2011) but play an essential role in the symptom exacerbation in patients with CRS (Rowan et al., 2015). All this evidence supports the role of the transient viral infection as the initial inflammatory stimulus in the pathogenesis of acute CRS exacerbations. However, it is relatively harder to identify key viruses that exacerbate CRS compared to ARS due to the multifactorial nature of CRS exacerbation.

\section{BACTERIOLOGY IN THE ACUTE CRS EXACERBATION}

While bacteria may trigger acute infectious exacerbations (Bose et al., 2016), the role of bacteria in acute CRS exacerbation is not completely understood. The most commonly cultured microbiota during acute exacerbations of CRS included Staphylococcus aureus, Pseudomonas aeruginosa, and other common pathogens (Streptococcus pneumonia, Haemophilus influenza, Moraxella catarrhalis, or Streptococcus pyogenes) (Cincik and Ferguson, 2006; Liu et al., 2013). Besides, S. pneumoniae and $H$. influenzae were found more frequently in patients with acute CRS exacerbation compared to those with CRS without frequent acute exacerbations (Brook, 2006). Also, the identified organisms were predominantly anaerobic, which was similar to those generally identified in CRS (Prevotella, Porhyromonas, Peptostreptococcus, and Fusobacterium subspecies). A study by Merkley et al. concluded that bacterial abundance was increased, but diversity was decreased during acute exacerbations of CRS (Merkley et al., 2015). These studies support the hypothesis of microbial imbalance as a critical driver of acute CRS exacerbation.

As a chronic inflammatory airway disease, CRS is characterized by mucosal microbiota dysbiosis (Lee et al., 2018). Under a specific predisposing condition, patients with CRS experience acute and transient alternations of the mucosal microbiota, which may contribute to the sinus infection. It has been well-recognized that viral infection plays an initiating role in the pathogenesis of acute CRS exacerbation, and a bacterial infection occurs as the secondary event. It can be speculated that the host response to viral infection is likely to influence susceptibility to acute CRS exacerbation. A better understanding of the biologic mechanisms of host susceptibility to viral infection will be crucial for developing more effective preventions and treatments aimed at improving the quality of life and thereby reducing the high cost in patients with CRS.

\section{IMMUNOLOGICAL FEATHERS OF ACUTE EXACERBATION OF CRS}

Acute exacerbation of CRS is increasingly being recognized as a distinct clinical manifestation of CRS that should be routinely evaluated in patients with CRS (Divekar et al., 2015; Banoub et al., 2018). Immunologic changes that occur during exacerbation may help physicians understand the pathogenesis of this acute phase of CRS. Rank and colleagues found that the levels of IL-6, eosinophil major basic protein (MBP), myeloperoxidase (MPO), eosinophil-derived neurotoxin, and uric acid in nasal secretion samples during CRSwNP exacerbation were significantly elevated when compared with the baseline measurements (Rank et al., 2013). What is more, the level of IL-6 significantly and positively correlated with both the levels of MBP and MPO. Increased IL-6 response has been associated with the onset of the viral upper respiratory tract infection in healthy individuals or virus-induced asthma exacerbations (Zhu et al., 1996; Jackson and Johnston, 2010). An epidemiological study also indicated that acute exacerbations of chronic rhinosinusitis occurred in the winter season during which viral infections are known to be prevalent, which implied a potential relationship between CRS disease activity and viral infection (Rank et al., 2010).

Systemic immune responses during exacerbation in patients with CRSwNP were also explored (Divekar et al., 2015). It showed that vascular endothelial growth factor (VEGF) and granulocyte-macrophage colony-stimulating factor (GM-CSF) levels in serum were significantly increased in CRSwNP patients during exacerbation when compared to control subjects or 
their baseline values. As the fact that VEGF and GM-CSF may play essential roles in tissue remodeling, and innate and adaptive immunity of nasal and sinus mucosa, future studies are warranted to investigate their exact role in the pathological changes in patients with CRS during exacerbation. These works have provided new insights into the pathophysiology of CRSwNP exacerbation. However, it should also be pointed out that the animal model of CRS with acute exacerbation is still lacking, and a new model would be helpful to elucidate its pathophysiological mechanism.

\section{CURRENT MEDICAL TREATMENT FOR PATIENTS WITH ACUTE CRS EXACERBATION}

Current guidelines recommend the use of short-term antibiotics in patients with acute CRS exacerbation for symptomatic relief (Fokkens et al., 2012; Peters et al., 2014; Orlandi et al., 2016). Non-macrolide antibiotics (i.e., cefuroxime, ofloxacin, cefixime, amoxicillin with or without clavulanic acid) comprises the mainstay of the short-term antibacterial therapy in CRS patients with the most significant benefit in CRS exacerbations with a positive culture (Gehanno and Cohen, 1993; Huck et al., 1993; Namyslowski et al., 2002; Adelson and Adappa, 2013; Hoza et al., 2013). There is only one RCT study about the antibiotics treatment of acute CRS exacerbation (Sabino et al., 2017). It showed that amoxicillin-clavulanate for 14 days did not change the clinical course of acute CRS exacerbation compared with placebo and the addition of an oral antibiotic to ongoing topical intranasal steroid spray did not provide additional benefit during the management of acute CRS exacerbation. The study also pointed out that the sample size $(n=21)$ was relatively small, which might lead to the inherent risks of committing biased conclusions. A recent review has discussed the role of macrolide treatment in patients with acute CRS exacerbation (Oakley et al., 2017). The high-dose macrolide antibiotics are typically involved in the treatment of acute CRS exacerbation, especially in penicillin-allergic patients, and a therapeutic dose is usually administered for 10 days. However, the current literature about the macrolide therapy that focused on the acute CRS exacerbation is still lacking, and further studies are needed in the future. In addition to antibiotic treatment, other medical treatment has also been reported. A retrospective

\section{REFERENCES}

Adelson, R. T., and Adappa, N. D. (2013). What is the proper role of oral antibiotics in the treatment of patients with chronic sinusitis? Curr. Opin. Otolaryngol. Head Neck Surg. 21, 61-68. doi: 10.1097/MOO.0b013e3283 5 ac625

Bachert, C., Zhang, N., Hellings, P. W., and Bousquet, J. (2018). Endotype-driven care pathways in patients with chronic rhinosinusitis. J. Allergy Clin. Immunol. 141, 1543-1551. doi: 10.1016/j.jaci.2018.03.004

Banoub, R. G., Phillips, K. M., Hoehle, L. P., Caradonna, D. S., Gray, S. T., and Sedaghat, A. R. (2018). Relationship between chronic rhinosinusitis exacerbation frequency and asthma control. Laryngoscope 128, 1033-1038. doi: 10.1002/lary.26901 study by Chaudhry et al. showed that topical triamcinolone acetonide (TA) and carboxymethylcellulose (CMC) foam for acute exacerbation of CRSwNP could significantly decrease SNOT-22 scores and the overall prednisone use in postoperative CRSwNP patients (Chaudhry et al., 2014). A recent review by Miyake and Bleier pointed out that topical medications might have an advantage over oral antibiotics for the treatment of acute CRS exacerbations (Miyake and Bleier, 2019). Lacking evidencebased treatment recommendations for acute CRS exacerbation, therefore, requires further studies on this disease status, and large-high-quality RCTs would help determine the best medical therapy to manage patients with acute CRS exacerbation.

\section{CONCLUSION AND FUTURE RESEARCH DIRECTION}

Acute CRS exacerbation has gained increasing attention due to its significant influence on patients' quality of life and healthcare cost. As a distinct form of CRS, acute CRS exacerbation can be triggered by viruses and then follows with bacterial infections, which might be the result caused by the imbalance among the bacterial species within the sinus cavities. There have been significant advances in understanding the etiology and immunological feathers of acute CRS exacerbation. Nevertheless, consensus definition, diagnostic criterion, biomarkers to differentiate acute CRS exacerbation from CRS, assessment of disease severity, and evidence-based treatment options for acute CRS exacerbation are still lacking.

\section{AUTHOR CONTRIBUTIONS}

DW drafted the manuscript. BB and YW reviewed and revised this manuscript.

\section{FUNDING}

This study was supported by the Natural Science Foundation of China (81670903), Capital Health Research and Development of Special Fund (2018-2-2065), Beijing Municipal Administration of Hospitals Ascent Plan (DFL20150602), Beijing Key Laboratory of upper airway dysfunction related cardiovascular diseases (BZ0377), and Beijing Hospitals Authority Youth Programme (QML20190617). Acute radiology rarely confirms sinus disease in suspected recurrent acute rhinosinusitis. Int. Forum Allergy Rhinol. 7, 726-733. doi: 10.1002/alr.21925

Basharat, U., Aiche, M. M., Kim, M. M., Sohal, M., and Chang, E. H. (2019). Are rhinoviruses implicated in the pathogenesis of sinusitis and chronic rhinosinusitis exacerbations? A comprehensive review. Int. Forum Allergy Rhinol. 9, 1159-1188. doi: 10.1002/alr.22403

Bhattacharyya, N., Gopal, H. V., and Lee, K. H. (2004). Bacterial infection after endoscopic sinus surgery: a controlled prospective study. Laryngoscope 114, 765-767. doi: 10.1097/00005537-200404000-00032

Bhattacharyya, N., Grebner, J., and Martinson, N. G. (2012). Recurrent acute rhinosinusitis: epidemiology and health care cost burden. Otolaryngology 146, 307-312. doi: 10.1177/0194599811426089 
Bhattacharyya, N., and Kepnes, L. J. (1999). The microbiology of recurrent rhinosinusitis after endoscopic sinus surgery. Arch. Otolaryngol. 125, 1117-1120. doi: 10.1001/archotol.125.10.1117

Bose, S., Grammer, L. C., and Peters, A. T. (2016). Infectious chronic rhinosinusitis. J. Allergy Clin. Immunol. 4, 584-589. doi: 10.1016/j.jaip.2016.04.008

Brook, I. (2006). Bacteriology of chronic sinusitis and acute exacerbation of chronic sinusitis. Arch. Otolaryngol. 132, 1099-1101. doi: 10.1001/archotol.132.10.1099

Brook, I. (2016). Microbiology of chronic rhinosinusitis. Eur. J. Clin. Microbiol. Infect. Dis. 35, 1059-1068. doi: 10.1007/s10096-016-2640-x

Brook, I., Foote, P. A., and Frazier, E. H. (2005). Microbiology of acute exacerbation of chronic sinusitis. Ann. Otol. Rhinol. Laryngol. 114, 573-576. doi: $10.1177 / 000348940511400714$

Campbell, A. P., Phillips, K. M., Hoehle, L. P., Feng, A. L., Bergmark, R. W., Caradonna, D. S., et al. (2017). Depression symptoms and lost productivity in chronic rhinosinusitis. Ann. Allergy Asthma Immunol. 118, 286-289. doi: 10.1016/j.anai.2016.12.012

Cao, P.-P., Wang, Z.-C., Schleimer, R. P., and Liu, Z. (2018). Pathophysiologic mechanisms of chronic rhinosinusitis and their roles in emerging disease endotypes. Ann. Allergy Asthma Immunol. 122, 33-40. doi: $10.1016 /$ j.anai.2018.10.014

Chaudhry, A. L., Chaaban, M. R., Ranganath, N. K., and Woodworth, B. A. (2014). Topical triamcinolone acetonide/carboxymethylcellulose foam for acute exacerbations of chronic rhinosinusitis/nasal polyposis. Am. J. Rhinol. Allergy 28, 341-344. doi: 10.2500/ajra.2014.28.4053

Cho, G. S., Moon, B.-J., Lee, B.-J., Gong, C.-H., Kim, N. H., Kim, Y.-S., et al. (2013). High rates of detection of respiratory viruses in the nasal washes and mucosae of the patients with chronic rhinosinusitis. J. Clin. Microbiol. 51, 979-984. doi: 10.1128/JCM.02806-12

Chung, S. D., Hung, S. H., Lin, H. C., and Lin, C. C. (2014). Health care service utilization among patients with chronic rhinosinusitis: a population-based study. Laryngoscope 124, 1285-1289. doi: 10.1002/lary.24500

Cincik, H., and Ferguson, B. J. (2006). The impact of endoscopic cultures on care in rhinosinusitis. Laryngoscope 116, 1562-1568. doi: 10.1097/01.mlg.0000230402.66579.07

Costa, C., Garzaro, M., Boggio, V., Sidoti, F., Simeone, S., Raimondo, L., et al. (2014). Detection of herpesviruses 1-6 and community-acquired respiratory viruses in patients with chronic rhinosinusitis with nasal polyposis. Intervirology 57, 101-105. doi: 10.1159/000358880

Divekar, R. D., Samant, S., Rank, M. A., Hagan, J., Lal, D., O’Brien, E. K., et al. (2015). Immunological profiling in chronic rhinosinusitis with nasal polyps reveals distinct VEGF and GM-CSF signatures during symptomatic exacerbations. Clin. Exp. Allergy 45, 767-778. doi: 10.1111/ cea.12463

Dutta, M., and Ghatak, S. (2013). Acute exacerbation of chronic rhinosinusitis (AECRS) with orbital complications in an atrophic rhinitis patient: a mere co-incidence? J. Clin. Diagn. Res. 7:2973. doi: 10.7860/JCDR/2013/ 6461.3814

Eloy, P., Poirrier, A. L., De Dorlodot, C., Van Zele, T., Watelet, J. B., and Bertrand, B. (2011). Actual concepts in rhinosinusitis: a review of clinical presentations, inflammatory pathways, cytokine profiles, remodeling, and management. Curr. Allergy Asthma Rep. 11, 146-162. doi: 10.1007/s11882-011-0180-0

Fokkens, W. J., Lund, V. J., Mullol, J., Bachert, C., Alobid, I., Baroody, F., et al. (2012). European position paper on rhinosinusitis and nasal polyps 2012. Rhinology.50, 1-12. doi: 10.4193/Rhino50E2

Gehanno, P., and Cohen, B. (1993). Effectiveness and safety of ofloxacin in chronic otitis media and chronic sinusitis in adult outpatients. Eur. Arch. Oto-Rhino-Laryngol. 250, S13-S14. doi: 10.1007/BF02540110

Gwaltney, J. M. Jr., Phillips, C. D., Miller, R. D., and Riker, D. K. (1994). Computed tomographic study of the common cold. New Engl. J. Med. 330, 25-30. doi: 10.1056/NEJM199401063300105

Hafner, B., Davris, S., Riechelmann, H., Mann, W. J., and Amedee, R. G. (1997). Endonasal sinus surgery improves mucociliary transport in severe chronic sinusitis. Am. J. Rhinol. 11, 271-276. doi: 10.2500/105065897781446612

Hamilos, D. L. (2014). Host-microbial interactions in patients with chronic rhinosinusitis. J. Allergy Clin. Immunol. 133, 640-653.e644. doi: 10.1016/j.jaci.2013.06.049
Hamilos, D. L. (2015). Drivers of chronic rhinosinusitis: inflammation versus infection. J. Allergy Clin. Immunol. 136, 1454-1459. doi: 10.1016/j.jaci.2015.10.011

Hastan, D., Fokkens, W., Bachert, C., Newson, R., Bislimovska, J., Bockelbrink, A., et al. (2011). Chronic rhinosinusitis in Europe-an underestimated disease. A GA2LEN study. Allergy 66, 1216-1223. doi: 10.1111/j.1398-9995.2011.02646.x

Hirsch, A. G., Stewart, W. F., Sundaresan, A. S., Young, A. J., Kennedy, T. L., Scott Greene, J., et al. (2017). Nasal and sinus symptoms and chronic rhinosinusitis in a population-based sample. Allergy 72, 274-281. doi: 10.1111/all.13042

Hoehle, L. P., Phillips, K. M., Bergmark, R. W., Caradonna, D. S., Gray, S. T., and Sedaghat, A. R. (2016). Symptoms of chronic rhinosinusitis differentially impact general health-related quality of life. Rhinology 54, 316-322. doi: 10.4193/Rhin16.211

Hoza, J., Salzman, R., Stárek, I., Schalek, P., and Kellnerová, R. (2013). Efficacy and safety of erdosteine in the treatment of chronic rhinosinusitis with nasal polyposis-a pilot study. Rhinology 51, 323-327. doi: 10.4193/Rhin13.039

Huck, W., Reed, B. D., Nielsen, R. W., Ferguson, R. T., Gray, D. W., Lund, G. K., et al. (1993). Cefaclor vs. amoxicillin in the treatment of acute, recurrent, and chronic sinusitis. Arch. Fam. Med. 2, 497-503. doi: 10.1001/archfami.2.5.497

Ikeda, K., Yokoi, H., Kusunoki, T., Saitoh, T., Yao, T., Kase, K., et al. (2011). Bacteriology of recurrent exacerbation of postoperative course in chronic rhinosinusitis in relation to asthma. Auris Nasus Larynx 38, 469-473. doi: 10.1016/j.anl.2010.10.009

Jackson, D. J., and Johnston, S. L. (2010). The role of viruses in acute exacerbations of asthma. J. Allergy Clin. Immunol. 125, 1178-1187. doi: 10.1016/j.jaci.2010.04.021

Kuiper, J. R., Hirsch, A. G., Bandeen-Roche, K., Sundaresan, A. S., Tan, B. K., Schleimer, R. P., et al. (2018). Prevalence, severity, and risk factors for acute exacerbations of nasal and sinus symptoms by chronic rhinosinusitis status. Allergy 73, 1244-1253. doi: 10.1111/all.13409

Lan, F., Zhang, N., Holtappels, G., Ruyck, N. D., Krysko, O., Crombruggen, K. V., et al. (2018). Staphylococcus aureus induces mucosal type 2 immune response via epithelial cell derived cytokines. Am. J. Respir. Crit. Care Med. 198, 452-463. doi: 10.1164/rccm.201710-2112OC

Lee, K., Pletcher, S. D., Lynch, S. V., Goldberg, A. N., and Cope, E. K. (2018). Heterogeneity of microbiota dysbiosis in chronic rhinosinusitis: potential clinical implications and microbial community mechanisms contributing to sinonasal inflammation. Front. Cell. Infect. Microbiol. 8:168. doi: $10.3389 /$ fcimb.2018.00168

Liao, B., Hu, C. Y., Liu, T., and Liu, Z. (2014). Respiratory viral infection in the chronic persistent phase of chronic rhinosinusitis. Laryngoscope 124, 832-837. doi: 10.1002/lary.24348

Liu, C. M., Soldanova, K., Nordstrom, L., Dwan, M. G., Moss, O. L., ContenteCuomo, T. L., et al. (2013). Medical therapy reduces microbiota diversity and evenness in surgically recalcitrant chronic rhinosinusitis. Int. Forum Allergy Rhinol. 3, 775-781. doi: 10.1002/alr.21195

Mahdavinia, M., Keshavarzian, A., Tobin, M. C., Landay, A., and Schleimer, R. P. (2016). A comprehensive review of the nasal microbiome in chronic rhinosinusitis (CRS). Clin. Exp. Allergy 46, 21-41. doi: 10.1111/cea. 12666

Merkley, M. A., Bice, T. C., Grier, A., Strohl, A. M., Man, L. X., and Gill, S. R. (2015). The effect of antibiotics on the microbiome in acute exacerbations of chronic rhinosinusitis. Int. Forum Allergy Rhinol. 5, 884-893. doi: 10.1002/alr.21591

Miyake, M. M., and Bleier, B. S. (2019). Future topical medications in chronic rhinosinusitis. Int. Forum Allergy Rhinol. 9, S32-S46. doi: 10.1002/alr.22341

Namyslowski, G., Misiolek, M., Czecior, E., Malafiej, E., Orecka, B., Namyslowski, P., et al. (2002). Comparison of the efficacy and tolerability of amoxycillin/clavulanic acid $875 \mathrm{mg}$ bid with cefuroxime $500 \mathrm{mg}$ bid in the treatment of chronic and acute exacerbation of chronic sinusitis in adults. $J$. Chemother. 14, 508-517. doi: 10.1179/joc.2002.14.5.508

Oakley, G. M., Harvey, R. J., and Lund, V. J. (2017). The role of macrolides in chronic rhinosinusitis (CRSsNP and CRSwNP). Curr. Allergy Asthma Rep. 17:30. doi: 10.1007/s11882-017-0696-z

Orlandi, R. R., Kingdom, T. T., Hwang, P. H., Smith, T. L., Alt, J. A., Baroody, F. M., et al. (2016). International consensus statement on allergy and rhinology: rhinosinusitis. Int. Forum Allergy Rhinol. 6(Suppl 1), S22-S209. doi: $10.1002 /$ alr.21695 
Pedersen, M., Sakakura, Y., Winther, B., Brofeldt, S., and Mygind, N. (1983). Nasal mucociliary transport, number of ciliated cells, and beating pattern in naturally acquired common colds. Eur. J. Respir. Dis. Suppl. 128, 355-365.

Peters, A. T., Spector, S., Hsu, J., Hamilos, D. L., Baroody, F. M., Chandra, R. K., et al. (2014). Diagnosis and management of rhinosinusitis: a practice parameter update. Ann. Allergy Asthma Immunol. 113, 347-385. doi: 10.1016/j.anai.2014.07.025

Phillips, K. M., Hoehle, L. P., Bergmark, R. W., Caradonna, D. S., Gray, S. T., and Sedaghat, A. R. (2017). Acute exacerbations mediate quality of life impairment in chronic rhinosinusitis. J. Allergy Clin. Immunol. 5, 422-426. doi: 10.1016/j.jaip.2016.09.015

Poetker, D. M., Litvack, J. R., Mace, J. C., and Smith, T. L. (2008). Recurrent acute rhinosinusitis: presentation and outcomes of sinus surgery. Am. J. Rhinol. 22, 329-333. doi: 10.2500/ajr.2008.22.3177

Rank, M. A., Hagan, J. B., Samant, S. A., and Kita, H. (2013). A proposed model to study immunologic changes during chronic rhinosinusitis exacerbations: data from a pilot study. Am. J. Rhinol. Allergy 27, 98-101. doi: 10.2500/ajra.2013.27.3850

Rank, M. A., Wollan, P., Kita, H., and Yawn, B. P. (2010). Acute exacerbations of chronic rhinosinusitis occur in a distinct seasonal pattern. J. Allergy Clin. Immunol. 126:168. doi: 10.1016/j.jaci.2010. 03.041

Rosenfeld, R. M., Piccirillo, J. F., Chandrasekhar, S. S., Brook, I., Ashok Kumar, K., Kramper, M., et al. (2015). Clinical practice guideline (update): adult sinusitis. Otolaryngology 152(2_Suppl.), S1-S39. doi: 10.1177/0194599815572097

Rowan, N. R., Lee, S., Sahu, N., Kanaan, A., Cox, S., Phillips, C. D., et al. (2015). The role of viruses in the clinical presentation of chronic rhinosinusitis. Am. J. Rhinol. Allergy 29, e197-e200. doi: 10.2500/ajra.2015.29.4242

Rudmik, L., Beswick, D. M., Alt, J. A., Bhattacharyya, N., Chester, A. C., Gray, S. T., et al. (2018). Appropriateness criteria for surgery in the management of adult recurrent acute rhinosinusitis. Laryngoscope 129, 37-44. doi: 10.1002/lary. 27438

Rudmik, L., Smith, T. L., Schlosser, R. J., Hwang, P. H., Mace, J. C., and Soler, Z. M. (2014). Productivity costs in patients with refractory chronic rhinosinusitis. Laryngoscope 124, 2007-2012. doi: 10.1002/lary.24630

Sabino, H. A. C., Valera, F. C. P., Aragon, D. C., Fantucci, M. Z., Titoneli, C. C., Martinez, R., et al. (2017). Amoxicillin-clavulanate for patients with acute exacerbation of chronic rhinosinusitis: a prospective, double-blinded, placebocontrolled trial. Int. Forum Allergy Rhinol. 7, 135-142. doi: 10.1002/alr.21846

Schleimer, R. P. (2017). Immunopathogenesis of chronic rhinosinusitis and nasal polyposis. Annu. Rev. Pathol. 12, 331-357. doi: 10.1146/annurev-pathol-052016-100401

Shi, J., Fu, Q., Zhang, H., Cheng, L., Wang, Y., Zhu, D., et al. (2015). Epidemiology of chronic rhinosinusitis: results from a cross-sectional survey in seven $\mathrm{C}$ hinese cities. Allergy 70, 533-539. doi: 10.1111/all.12577

Sivasubramaniam, R., and Douglas, R. (2018). The microbiome and chronic rhinosinusitis. World J. Otorhinolaryngol. Head Neck Surg. 4, 216-221. doi: 10.1016/j.wjorl.2018.08.004

Smith, K. A., Orlandi, R. R., and Rudmik, L. (2015). Cost of adult chronic rhinosinusitis: a systematic review. Laryngoscope 125, 1547-1556. doi: 10.1002/lary.25180
Smith, S. S., Evans, C. T., Tan, B. K., Chandra, R. K., Smith, S. B., and Kern, R. C. (2013). National burden of antibiotic use for adult rhinosinusitis. J. Allergy Clin. Immunol. 132, 1230-1232. doi: 10.1016/j.jaci.2013.07.009

Sohn, H. G., Park, S. J., Ryu, I. S., Lim, H. W., Song, Y. J., and Yeo, N.-K. (2018). Comparison of clinical presentation and surgical outcomes between recurrent acute rhinosinusitis and chronic rhinosinusitis. Ann. Otol. Rhinol. Laryngol. 127, 763-769. doi: 10.1177/0003489418792942

Tan, K. S., Yan, Y., Ong, H. H., Chow, V. T., Shi, L., and Wang, D.-Y. (2017). Impact of respiratory virus infections in exacerbation of acute and chronic rhinosinusitis. Curr. Allergy Asthma Rep. 17:24. doi: 10.1007/s11882-017-0693-2

Tieu, D. D., Kern, R. C., and Schleimer, R. P. (2009). Alterations in epithelial barrier function and host defense responses in chronic rhinosinusitis. J. Allergy Clin. Immunol. 124, 37-42. doi: 10.1016/j.jaci.2009.04.045

Wagner, B. M., Waite, D. W., Hoggard, M., Taylor, M. W., Biswas, K., and Douglas, R. G. (2017). Moving beyond descriptions of diversity: clinical and research implications of bacterial imbalance in chronic rhinosinusitis. Rhinology 55, 291-297. doi: 10.4193/Rhin17.135

Wang, J., Watanabe, S., Matsukura, S., and Suzaki, H. (2009). Double-stranded RNA poly (I: C) enhances matrix metalloproteinase mRNA expression in human nasal polyp epithelial cells. Acta Otolaryngol. 129, 105-109. doi: 10.1080/00016480902911979

Wang, X., Zhang, N., Glorieux, S., Holtappels, G., Vaneechoutte, M., Krysko, O., et al. (2012). Herpes simplex virus type 1 infection facilitates invasion of Staphylococcus aureus into the nasal mucosa and nasal polyp tissue. PLoS ONE 7:e39875. doi: 10.1371/journal.pone.0039875

Wood, A. J., Antoszewska, H., Fraser, J., and Douglas, R. G. (2011). Is chronic rhinosinusitis caused by persistent respiratory virus infection? Int. Forum Allergy Rhinol. 1, 95-100. doi: 10.1002/alr.20030

Yamasaki, A., Hoehle, L. P., Phillips, K. M., Feng, A. L., Campbell, A. P., Caradonna, D. S., et al. (2018). Association between systemic antibiotic and corticosteroid use for chronic rhinosinusitis and quality of life. Laryngoscope 128, 37-42. doi: 10.1002/lary.26778

Yeo, N. K., and Jang, Y. J. (2010). Rhinovirus infection-induced alteration of tight junction and adherens junction components in human nasal epithelial cells. Laryngoscope 120, 346-352. doi: 10.1002/lary.20764

Zhu, Z., Tang, W., Ray, A., Wu, Y., Einarsson, O., Landry, M. L., et al. (1996). Rhinovirus stimulation of interleukin-6 in vivo and in vitro. Evidence for nuclear factor kappa B-dependent transcriptional activation. J. Clin. Invest. 97, 421-430. doi: 10.1172/JCI118431

Conflict of Interest: The authors declare that the research was conducted in the absence of any commercial or financial relationships that could be construed as a potential conflict of interest.

Copyright (C) $2019 \mathrm{Wu}$, Bleier and Wei. This is an open-access article distributed under the terms of the Creative Commons Attribution License (CC BY). The use, distribution or reproduction in other forums is permitted, provided the original author(s) and the copyright owner(s) are credited and that the original publication in this journal is cited, in accordance with accepted academic practice. No use, distribution or reproduction is permitted which does not comply with these terms. 